\title{
An Empirical Study on the National Heterogeneity of High-End Manufacturing Technology Innovation and GVC's Division of Labor Status
}

\author{
Lei Liang $\mathbb{B D}^{1}$ and Yawen Liang $\mathbb{D}^{2}$ \\ ${ }^{1}$ School of Economics and Business Administration, Heilongjiang University, Harbin, Heilongjiang 150080, China \\ ${ }^{2}$ School of Arts and Law, Northeastern University, Shenyang, Liaoning 110167, China \\ Correspondence should be addressed to Lei Liang; 2019045@hlju.edu.cn
}

Received 4 August 2021; Revised 24 October 2021; Accepted 9 November 2021; Published 25 November 2021

Academic Editor: Anna M. Gil-Lafuente

Copyright (C) 2021 Lei Liang and Yawen Liang. This is an open access article distributed under the Creative Commons Attribution License, which permits unrestricted use, distribution, and reproduction in any medium, provided the original work is properly cited.

\begin{abstract}
Although the relationship between technological innovation and the status of the global value chain's (GVC) division of labor has been essentially affirmed by academia, the direct regression of all countries does not account for national differences pertaining to different economic development levels. This paper divides the countries selected for this study into developed and developing countries and then conducts empirical tests on two sample sets to explore the heterogeneity of technological innovation and GVC division of labor status. The results reveal the following: (1) in developed countries, the GVC division of labor status of high-end manufacturing is generally higher than that of developing countries; (2) in developed countries, the technological innovation of high-end manufacturing plays a significant role in promoting GVC's division of labor, while developing countries have a significant inhibitory effect; and (3) staff input and financial developmental levels have significantly promoted GVC's status in the division of labor. Earlier studies have shown that, in developing countries, technological innovation in high-end manufacturing industries does not fully serve the goal of exporting intermediate goods. This study's conclusions offer a new method of explaining the nature of a given country, the logic of technological innovation, and the differences in the GVC division of labor status.
\end{abstract}

\section{Introduction}

Today, the world is facing "major changes unseen in a century." Furthermore, major changes have occurred in the global context. The integration of countries into the global value chain-doing so based on each country's own comparative advantages-is an important way for individual countries to seek both economic development and international competitive advantages. However, the value creation capabilities of different links are distinctive [1]. Only by strategically occupying specific links of the global value chain can we garner the greatest dividend of the division of labor, occupy a dominant position, and govern the global value chain. The GVC division of labor status of high-end manufacturing is central to measuring a country's core competitiveness; therefore, enhancing that status is a strategic goal in the competition among countries worldwide. As a leading and strategic industry, high-end manufacturing has all the characteristics of the technology sector: high added value and a strong driving force. Compared to traditional manufacturing, high-end manufacturing relies on the advantages that high-tech and high-end equipment confer; indeed, its strength in terms of science and technology is its competitive attribute. Continuous technological innovation is vital to the ongoing development of high-end manufacturing.

Given the deepening interdependence of economic globalization, global competition in high-end manufacturing has become, essentially, a technological competition. Economically dominant countries encourage and promote technological innovation. These countries do this, aiming to develop high-end manufacturing through technological 
innovation that is compatible with their own level of economic development and industrial structure. However, in the GVC division of labor system, the status of developed countries versus developing countries differs significantly. Developed countries operate as more strategic, value-added links in the $G$ while developing countries are mostly locked into the lower end of the value chain. Thus, the question becomes: Is the formation of such a division of labor a result simply of developed countries' higher levels of technological innovation and developing countries' lower levels?

In light of this question, this paper attempts to explore the impact of technological innovation on the GVC division of labor status. It also tries to identify whether technological innovation plays either the same or a similar role in the GVC division of labor status of high-end manufacturing in developed and developing countries. When compared to previous studies, this paper offers a possible contribution to the corpus of academic literature. These contributions are as follows: (1) with regard to research, this study breaks through the traditional method of inquiry by exploring the heterogeneous impact of technological innovation on the GVC division of labor status in developed and developing countries; (2) in terms of methodology, this paper attempts to transform the GVC division of labor measurement framework, which is based on the domestic value-added of final product exports, into a domestic value-added measurement framework that is based on exporting intermediate products. This method enables this study largely to avoid the "statistical illusion."

\section{Literature Review and Background}

Scholars, both in China and abroad, have for many years intensively cultivated the calculation method of GVC division of labor status. In fact, in recent years, the measurement of value-added trade has become dominant. In fact, both the OECD and the WTO proposed this concept in 2011, which aims to break the traditional accounting method of trade benefits and establish a statistical framework that is more aligned with the actual benefits of international trade. The value-added trade statistics system is based on vertical specialization and forms a new GVC measurement framework by relaxing and restricting assumptions that do not conform to the real-world context. The data basis of this measurement framework is the world Input-output table (WIOT).

For the past two decades, scholars in China and abroad have used WIOT to explore the status of the division of labor in the GVC from the perspective of value-added, and they have indeed achieved fruitful results. Among them, the most representative is the measurement framework based on the Hummels et al. (HIY) method [2]. On this basis, Wang et al. (2009, hereafter referred to as WWP) extended HIY's method of vertical specialization and established an accounting framework that includes several countries based on the international input-output model. This framework explains how value-added within the multicountry production chain can be reconfigured as each participating country's net contribution [3]. Afterward, the KWW method [4] was proposed by Koopman, which essentially extended WWP, as its measurement method was consistent with WWP.

Technological innovation is an important factor that affects the status of GVC's division of labor. Both traditional economic growth theory and neoclassical economic growth theory expound on the relationship between technological innovation and economic growth. A key distinction between the two theories is that traditional economic theory argues that innovation and technological progress are the only sources of economic growth, while neoclassical economic growth theory contends that long-term economic growth can be achieved only by technological progress. Research based on countries' international competitiveness regarding exports often argues that innovation plays an important role in promoting a country's trade growth and structural optimization and that it is a critical factor in determining the strength of a product's international competitiveness [5]. Technological developmental capacities and technology transformation capabilities can significantly enhance a country's international competitiveness [6]. Furthermore, there is a long-term, symbiotic relationship between technology research and development (R\&D) input and output rate and trade competitiveness [7]. Research based on the export markup rate tends to argue that enterprise's product innovation has increased the export markup rate and, furthermore, that the improvement effect of different regions is heterogeneous [8]. From the perspective of domestic valueadded exports, Zheng and Zheng considered the role of intermediate product innovation on GVC's division of labor status, and the content that manufacturing intermediate product innovation has a lagging, yet cumulative, effect on the domestic export value-added rate, but that it also has an indirect effect. What is more obvious, however, are the promotion of the export value-added rate and that of hightech industries [9]. For example, Yang and Tian used China's manufacturing industry to confirm that technological progress has a negative linear relationship to the status of the GVC division of labor [10]. Simultaneously, other scholars argue that the impact of technological innovation on the status of GVCs cannot be generalized. For example, Yu and Liu suggest that China's independent innovation capacity has no significant impact on export trade, while technological innovation from abroad has both significant and positive effects on export trade [11]. Wang and Fan's research shows that the impact of innovation on the complexity of export technology is not a simple linear relationship but in fact has a nonlinear characteristic of diminishing marginal efficiency and that innovation output can significantly increase the complexity of export technology [12].

Through careful analysis, this study has found that the status of GVC's division of labor has formed a relatively mature measurement framework and that scholars hold a positive attitude toward the relationship between technological innovation and GVC's division of labor from a general and long-term perspective. However, most studies rely on a specific country or industry as their identified research subject and often with the aim of verifying the relationship between the two. Therefore, there is still much 
room for research to enhance the academic knowledge base about the status of technological innovation and the GVC division of labor. The relationship between technological innovation and the status of GVC's division of labor to industries in both developed and developing countries as a research subject has not yet been clarified. Thus, the following questions are salient: Are there differences in the relationship between developed and developing countries? If so, why is there such a difference? What are other important factors that may be affecting the status of GVC's division of labor? And do those factors play an indirect role in the relationship between technological innovation and GVC's division of labor status?

In light of these questions, this paper uses the InterCountry Input-Output Table of the WIOD in tandem with the methods proposed by Wang and KWW as the general frame of reference. This study has calculated the GVC division status of high-end manufacturing for 43 major countries based on their exports of intermediate goods. Additionally, this study has constructed a panel data model to empirically test the above questions and to clarify the relationship between technological innovation and GVC division of labor status in both developed and developing countries, thereby enriching the theory of technological innovation and GVC theory.

\section{Materials and Methods}

\subsection{Model Design and Method}

3.1.1. Model Design. The Cobb-Douglas (C.W.Cobb, Paul H.Douglas, 1992) production function describes the functional relationship among labor, capital, and other production factors and economic output. Furthermore, it can astutely reflect the nature and characteristics of changes in economic activity output. Given the continuous development of economic theory and social practice, the production function has likewise been continuously developed. The status of the GVC division of labor is measured by the domestic value-added of a country's export intermediate products. It also engages with the output of economic activities, and its status is closely related to capital, labor, technology, and other production factors. Therefore, it is possible to establish a functional relationship among the GVC division status of high-end manufacturing and labor input, capital input, technology level, and other factors, thereby reflecting the relationship between these factors and the GVC division status. This is expressed as follows:

$$
Y=A L^{\alpha} K^{\beta} .
$$

Here, $Y$ is the GVC division status of the high-end manufacturing industry; $A$ is the technical level; $L$ is the labor input; and $K$ is the capital input.

To understand fully the relationship and heterogeneity between technological innovation in high-end manufacturing and GVC's division of labor, this paper will conduct a grouping test on both developing and developed countries. Combining with Michael Porter's (Michael E.Porter, 1990) diamond model, this paper further expands the Cobb-Douglas production function and divides the factors that affect the upgrade into three categories: supply factors, demand factors, and environmental factors [13]. Among them, the supply factors include the input of labor, capital, technology, and other production factors and the overall input ratio. Demand factors include consumer or manufacturer's preferences for product demand, and environmental factors include industrial policy or institutional factors. Per previous academic studies, this paper uses four variables as the control variables, namely, professional staff input, fixed assets, financial development level, and openness to the outside world. Therefore, Model I is set as follows:

$$
\begin{aligned}
Y_{i t}= & \alpha_{0}+\alpha_{1} \ln \mathrm{PAT}_{i t}+\alpha_{2} \ln \mathrm{EMP}_{i t}+\alpha_{3} \ln \mathrm{AST}_{i t} \\
& +\alpha_{4} \ln \mathrm{FAC}_{i t}+\alpha_{5} \ln \mathrm{OWW}_{i t}+\varepsilon_{i t} .
\end{aligned}
$$

Here, $Y$ represents the domestic value-added rate of high-tech intermediate exports of country " $i$ " in year " $t$," which is the explaining variable that represents the GVC division of labor status of a country's high-end manufacturing industry. $\ln \mathrm{PAT}_{i t}$ represents the level of technology; $\ln \mathrm{EMP}_{i t}$ is the number of employees in highend manufacturing, and it measures the manpower input of a country's high-end manufacturing. $\ln \mathrm{AST}_{i t}$ indicates funding input, and $\ln \mathrm{FAC}_{i t}$ is the level of financial development. Finally, $\ln \mathrm{OWW}_{i t}$ indicates the degree of openness.

3.1.2. Indicator Description and Data Sources. In the research model of technological innovation and GVC division of labor status in high-end manufacturing, the data of explanatory variables come essentially from the subdatabases of the WIOD and the OECD.Stat database. Patents reflect the technology and achievements of independent intellectual property rights; furthermore, they can also fully reflect the technological innovation capabilities of a region [14]. Therefore, this paper uses the number of patent applications per 10,000 people in a given country as a proxy variable for the country's technological innovation. Finally, the data come from OECD Science, Technology, and R\&D Statistics. The specific calculation method is as follows:

$$
\mathrm{PAT}_{i t}=\frac{\text { patents }_{i t}}{\text { population }_{i t}} .
$$

Employment input is expressed by the total number of employees within the high-end manufacturing industry of each country and in each period. Capital investment utilizes stock indicators because changes to the GVC division of labor status in high-end manufacturing are a long-term process; rather than relying on a specific year of funding to achieve substantial changes, it is more advantageous to use stock data [15]. Due to the lack of base-period funding stock data, the fixed assets of high-end manufacturing in various countries are used to measure the capital stock of a country's high-end manufacturing. The data for the two indicators of employees and capital stock are derived from the STAN Database for Structural Analysis (ISIC Rev. 4, SNA08) copy in the OECD database. Finally, the financial development level indicator is measured by a country's government's total 
financial assets as a percentage of GDP. The calculation method is as follows:

$$
\mathrm{FNC}_{i t}=\frac{\text { fanacial }_{i t}}{\mathrm{GDP}_{i t}} .
$$

The level of opening to the outside world is measured by the ratio of the total import and export trade of a country's high-end manufacturing industry to GDP. The total import trade includes the imported intermediate products and final imported products of high-end manufacturing, and the total export trade includes export intermediates and final export. These four sets of data are all from WIOT in the WIOD products.

$$
\mathrm{OWW}_{i t}=\frac{\text { export }_{i t}^{\mathrm{inter}}+\text { export }_{i t}^{\mathrm{final}}+\text { import }_{i t}^{\mathrm{inter}}+\text { import }_{i t}^{\mathrm{inter}}}{\mathrm{GDP}_{i t}} .
$$

Because the GVC division of labor status of the major countries is based on the 2000-2014 Inter-Country InputOutput Table (WIOT), the data are current as of 2014. Therefore, the 2000-2014 panel data pertaining to high-end manufacturing industries in various countries are selected as foundational for performing this study's empirical research. The reporting countries for most of the indicators in the OECD database are limited to 35 OECD members, among which the number of developing countries is relatively small. Unfortunately, the missing data pertaining to is a serious issue. To ensure reliability, this study eliminated some of the countries that have serious defects with regard to Finally, this research selected 10 developing countries and 10 developed countries. The selected developing countries include China, the Czech Republic, Hungary, Latvia, Lithuania, Poland, Portugal, Slovakia, Slovenia, and Spain. Part of China's high-end manufacturing data comes from the "China High-tech Statistical Yearbook" from

on. The selected developed countries include Belgium, Canada, Denmark, Finland, France, Germany, Italy, Japan, the United Kingdom, and the United States.

$$
V_{\mathrm{int}}=V \cdot(I-A)^{-1} \cdot E=\left[\begin{array}{ccc}
\widehat{V A^{A}} & 0 & 0 \\
0 & \ddots & 0 \\
0 & \cdots & \widehat{V A^{G}}
\end{array}\right] \cdot\left[\begin{array}{ccc}
1-A^{A A} & \cdots & A^{A G} \\
\vdots & \ddots & \vdots \\
A^{G A} & \cdots & 1-A^{G G}
\end{array}\right] \cdot\left[\begin{array}{ccc}
\widehat{E_{\mathrm{int}}^{A}} & 0 & 0 \\
0 & \ddots & 0 \\
0 & \cdots & \widehat{E_{\mathrm{int}}^{G}}
\end{array}\right]
$$

The World Input-Output Database (WIOD), established by the European Union in , counts the flow of factors between countries and sectors in 35 subindustries among 27 EU member states and 16 major trading countries. The WIOD is the authoritative database recognized by most academics in the context of studying trade gains among countries. As of 2021, statistical data for the period

\subsection{Calculation of GVC Division of Labor Status of High-End Manufacturing Industries in Various Countries}

3.2.1. Calculation Method. Thus far, academia lacks consensus regarding the definition of high-end manufacturing. As such, there is no uniform statistical classification standard. However, academics generally agree on two aspects of the working definition of high-end manufacturing: industry and industrial chain links. From an industry perspective, high-end manufacturing is an industry inherently linked with advanced technological content, high added value, and competitiveness in the manufacturing industry. From the industrial chain perspective, high-end manufacturing belongs to the high-end link of a specific industrial chain. For the advantages that it confers to conducting empirical research, the definition of high-end manufacturing industry, used in this paper, includes both high-end industries and manufacturing industries that contain high-end production links.

Indeed, the measurement method of the division of labor, which is based on the intercountry input-output model, has made great progress. Among them, the valueadded trade accounting system has gradually replaced the traditional statistical system of total trade volume. On the one hand, the former eliminates the "statistical illusion" of traditional trade statistics; on the other, it can also calculate more accurately the profitability of countries participating in the division of labor in the GVC. Due to the real-world context, namely, the large-scale rise of processing trade, the traditional product competitive advantage has been supplanted by the competitive advantage of specific links (intermediate products). Furthermore, the products that the countries produce are used to develop export trade rather than to meet domestic demand. Intermediate trade is the direct carrier of the division of production factors by countries, its trade proportion is the basis for judging the degree of GVC division of labor, and it is also an important indicator of a country's ability to benefit from the GVC division of labor network [16]. Therefore, based on the calculation methods promoted by WWP (2009) and KWW (2010), this paper has selected the domestic value-added rate of intermediate exports as the measurement framework for a country's GVC division of labor status:

2000-2014 has been recorded. Therefore, this paper selects WIOD's noncompetitive input-output table (WIOT) as the source of the basic data for analyzing the status of the GVC division of labor. Based on the data provided by WIOT, this study has generated noncompetitive input-output tables of high-end manufacturing industries in various countries. Because these 43 countries or regions (hereafter referred to 
as countries) account for 85 percent of the global trade volume, this paper has created a noncompetitive inputoutput table that represents the high-end manufacturing industries within the selected 43 countries (see Table 1).

3.2.2. Calculation Result. Based on the calculation methodology promoted by both WWP (2009) and KWW (2010), the domestic value-added input of intermediate exports of high-end manufacturing in 43 major countries (according to trade output) has been estimated. Due to space limitations, this study lists only a selection of years for some countries (see Table 2).

One can see that, according to Table 2, the GVC division of labor status in developed countries is generally higher than that of developing countries. From the perspective of time and duration, in most countries, the status of the GVC division of labor fluctuates to varying degrees, and most show a downward trend. One can also observe, from Table 2, that the average domestic value-added rate of global highend manufacturing intermediate goods dropped from 0.383 in 2000 to 0.372 in 2014. During the nine years from 2005 to 2014 , the export value-added rate of high-tech intermediate products steadily and continuously declined, and the annual decline reached 7 percent.

\section{Results and Discussion}

4.1. An Empirical Study on the Status of Technological Innovation and GVC Division of High-End Manufacturing. This paper uses a panel data model to verify the status of technological innovation and the GVC division of labor in high-end manufacturing. Panel data is a combination of cross-sectional data and time-series data. The most prominent advantage is that it can overcome the problems of multicollinearity and missing variables in time-series analysis. It can provide more degrees of freedom for coefficient estimation to improve the accuracy and efficiency of the estimation. According to the above model setting, we use Stata 14.0 to perform regression analysis on the data and use robust standard errors to estimate. Descriptive statistics for each indicator are shown in Table 3.

According to Table 4, the effect of technological innovation on the status of GVC's division of labor is not significant, and this result does not conform to the objective law of innovation-driven value appreciation. In order to further explore the mechanism between technological innovation and the GVC division of labor status and find out the reasons for the empirical results of the comprehensive sample, the sample is divided into developing countries and developed countries, and the two types of countries are, respectively, grouped and regressed.

4.2. An Empirical Study on the Status of Technological Innovation and GVC Division of High-End Manufacturing in Developed Countries. Based on the panel data of high-end manufacturing in developed countries from 2000 to 2014, Stata 14.0 is used to conduct empirical research on technological innovation and the status of the GVC division of labor. The test results are shown in Table 5.

According to Table 5, developed countries' technological innovation has a significant positive impact on GVC's division of labor, with a significant level of 1 percent. Table 4 also shows that technological innovation has significantly promoted the upgrading of the GVC division of labor status when pertaining to high-end manufacturing in developed countries. As such, this further verifies that developed countries are the strategic link in the high-end manufacturing value chain. Human resource investment, fixed asset investment, and financial development level all have a significant and positive effect on the GVC division of labor status in high-end manufacturing. Those significant levels are 10 percent, 1 percent, and 1 percent, respectively. Finally, this suggests that both the optimization of resource structure and the development of finance have provided an advantageous foundation from which developed countries have developed high-end manufacturing and have also positioned themselves as strategic links in the value chain.

4.3. An Empirical Study on the Status of Technological Innovation and GVC Division of High-End Manufacturing in Developing Countries. As in the previous article, this study bases its research on the panel data of high-end manufacturing in developing countries from 2000 to 2014. As such, Stata 14.0 is used to conduct empirical research on technological innovation and the status of the GVC division of labor. The statistical results are shown in Table 6.

From the regression estimation results (Table 6), in developing countries, technological innovation has a negative impact on the GVC division of labor status, with a significant level of 10 percent. Table 6 further indicates that developing countries' technological innovation and the status of GVC's division of labor are not positively interdependent. This finding not only deviates from the high-tech inherent attributes of high-end manufacturing but also reflects, to a certain extent, the elemental structure of high-end manufacturing in developing countries that are embedded in the global value chain.

4.4. Extended Research. Technological innovation in developed and developing countries has opposite effects on GVC's division of labor status. Technological innovation should play a positive role in promoting the domestic valueadded export of high-end manufacturing intermediate products, but the actual situation of high-end manufacturing exports in developing countries violates this theory. Therefore, it is necessary to further explore the mechanism of action. This study uses stepwise regression to verify the influence of each factor on GVC's division of labor, forming Model 1 to Model 4.

4.4.1. Multiple Stepwise Regression Analysis of Developed Countries. Multiple stepwise regression gradually brings all the influencing factors that may affect $\mathrm{Y}$ into the regression equation; it also performs an F-test on each factor 
TABLE 1: Inter-Country Input-Output Table.

\begin{tabular}{|c|c|c|c|c|c|c|c|c|c|c|}
\hline & & & \multicolumn{4}{|c|}{ Intermediate use } & \multicolumn{3}{|c|}{ End use } & \multirow{2}{*}{$\begin{array}{c}\text { Total } \\
\text { output }\end{array}$} \\
\hline & & & $\begin{array}{c}\text { Country A } \\
1, \ldots, N\end{array}$ & $\begin{array}{c}\text { Country B } \\
1, \ldots, N\end{array}$ & $\begin{array}{l}\cdots \\
\cdots\end{array}$ & $\begin{array}{c}\text { Row } \\
1, \ldots, N\end{array}$ & Country A & Country B & ... Row & \\
\hline \multirow{5}{*}{$\begin{array}{l}\text { Intermediate } \\
\text { invest }\end{array}$} & Country A & $1, \ldots, N$ & $X^{A A}$ & $X^{A B}$ & & $X^{A R}$ & $Y^{A A}$ & $Y^{A B}$ & $\ldots Y^{A R}$ & $X^{A}$ \\
\hline & Country B & $1, \ldots, N$ & $X^{B A}$ & $X^{B B}$ & $\ldots$ & $X^{B R}$ & $Y^{B A}$ & $Y^{B B}$ & $\ldots Y^{B R}$ & $X^{B}$ \\
\hline & $\begin{array}{c}\ldots \\
\text { Row }\end{array}$ & $\begin{array}{c}\cdots \\
1, \ldots, N\end{array}$ & $\begin{array}{c}\ldots \\
X^{R A}\end{array}$ & $\begin{array}{c}\ldots \\
X^{R B}\end{array}$ & $\cdots$ & $\begin{array}{c}\ldots \\
X^{R R}\end{array}$ & 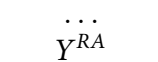 & $\ddot{Y^{R B}}$ & $\begin{array}{cc}\ldots & \ldots \\
\ldots & Y^{R R}\end{array}$ & $\begin{array}{l}\ldots \\
X^{R}\end{array}$ \\
\hline & Value-added & & $V^{A}$ & $V^{B}$ & & $V^{R}$ & & & & \\
\hline & $\begin{array}{c}\text { Total } \\
\text { investment }\end{array}$ & & $X^{A}$ & $X^{B}$ & $\ldots$ & $X^{R}$ & & & & \\
\hline
\end{tabular}

TABLE 2: GVC division of labor status in high-end manufacturing industries in the world.

\begin{tabular}{|c|c|c|c|c|c|}
\hline \multirow[b]{2}{*}{ Country } & \multicolumn{5}{|c|}{ Year } \\
\hline & 2002 & 2005 & 2008 & 2011 & 2014 \\
\hline Australia & 0.379 & 0.634 & 0.423 & 0.352 & 0.319 \\
\hline Austria & 0.388 & 0.666 & 0.454 & 0.385 & 0.369 \\
\hline Belgium & 0.367 & 0.409 & 0.442 & 0.349 & 0.341 \\
\hline Bulgaria & 0.401 & 0.610 & 0.455 & 0.395 & 0.378 \\
\hline Brazil & 0.345 & 0.640 & 0.269 & 0.210 & 0.114 \\
\hline Canada & 0.193 & 0.540 & 0.327 & 0.210 & 0.142 \\
\hline Switzerland & 0.372 & 0.635 & 0.396 & 0.333 & 0.288 \\
\hline China & 0.224 & 0.644 & 0.124 & 0.323 & 0.365 \\
\hline Germany & 0.596 & 1.000 & 0.607 & 0.714 & 0.867 \\
\hline France & 0.389 & 0.900 & 0.546 & 0.453 & 0.484 \\
\hline United Kingdom & 0.555 & 0.706 & 0.616 & 0.380 & 0.248 \\
\hline Indonesia & 0.379 & 0.627 & 0.423 & 0.362 & 0.322 \\
\hline India & 0.358 & 0.635 & 0.330 & 0.281 & 0.274 \\
\hline Ireland & 0.409 & 0.627 & 0.504 & 0.490 & 0.473 \\
\hline Italy & 0.454 & 0.709 & 0.546 & 0.363 & 0.431 \\
\hline Japan & 1.000 & 0.638 & 1.000 & 1.000 & 1.000 \\
\hline Korea & 0.389 & 0.644 & 0.807 & 0.598 & 0.779 \\
\hline Mexico & 0.000 & 0.023 & 0.029 & 0.000 & 0.000 \\
\hline Malta & 0.401 & 0.610 & 0.453 & 0.390 & 0.371 \\
\hline Netherlands & 0.527 & 0.692 & 0.640 & 0.411 & 0.237 \\
\hline Norway & 0.417 & 0.653 & 0.470 & 0.399 & 0.384 \\
\hline Poland & 0.434 & 0.624 & 0.483 & 0.386 & 0.372 \\
\hline Romania & 0.407 & 0.589 & 0.471 & 0.421 & 0.412 \\
\hline Russia & 0.366 & 0.741 & 0.245 & 0.236 & 0.163 \\
\hline Sweden & 0.374 & 0.744 & 0.428 & 0.393 & 0.380 \\
\hline Turkey & 0.376 & 0.630 & 0.420 & 0.351 & 0.337 \\
\hline Taiwan, China & 0.411 & 0.631 & 0.705 & 0.581 & 0.742 \\
\hline United States & 0.576 & 0.799 & 0.568 & 0.473 & 0.116 \\
\hline
\end{tabular}

TABLE 3: Descriptive statistics of various variables.

\begin{tabular}{lccccc}
\hline Variable & Average value & Standard error & Min & Max & Variable \\
\hline POS & 190.000 & 0.459 & 0.184 & 0.000 & 1.000 \\
PAT & 190.000 & 1.845 & 2.930 & -2.154 & 7.354 \\
EMP & 190.000 & 5.888 & 1.557 & 2.771 & 8.844 \\
AST & 190.000 & 9.542 & 2.890 & 3.989 & 17.060 \\
FNC & 190.000 & 3.538 & 0.457 & 2.822 & 4.827 \\
OWW & 190.000 & 11.760 & 1.791 & 7.525 \\
\hline
\end{tabular}

to ensure that each new significant variable is included in the regression equation. Variables are included which have a significant effect on $\mathrm{Y}$ until all insignificant factors have been added to the equation. The results of the stepby-step multivariate analysis of developed countries are shown in Table 7.
One can see from the regression results displayed in Models 1 through 4 that the level of technological innovation has always had a positive and significant influence on the status of GVC's division of labor, which is similar to Model 1's regression result. This illustrates even further both the robustness and reliability of the results. Notably, the four 
TABLE 4: Mixed estimation results of technological innovation and GVC division status of high-end manufacturing.

\begin{tabular}{lccccc}
\hline Variable & Coefficient & Standard error & $t$ & $P>|t|$ & \multicolumn{1}{c}{ Confidence interval } \\
\hline PAT & -0.006 & 0.006 & -0.900 & 0.378 & -0.018 \\
EMP & $0.127^{* * *}$ & 0.024 & 5.320 & 0.000 & 0.007 \\
AST & 0.012 & 0.008 & 1.510 & 0.149 & -0.005 \\
FAC & $0.058^{* * *}$ & 0.016 & 3.580 & 0.002 & 0.177 \\
OWW & $-0.084^{* * *}$ & 0.021 & -3.990 & 0.001 & 0.029 \\
_cons & $0.381^{* * *}$ & 0.125 & 3.050 & 0.007 & -0.128 \\
\hline
\end{tabular}

${ }^{* * *},{ }^{* *}$, and ${ }^{*}$, respectively, indicate that the significance levels are 1 percent, 5 percent, and 10 percent.

TABLE 5: Mixed estimation results of technological innovation and GVC division status of high-end manufacturing in developed countries.

\begin{tabular}{lccccr}
\hline Variable & Coefficient & Standard error & $t$ & $P>|t|$ & Confidence interval \\
\hline PAT & $0.393^{* * *}$ & 0.037 & 10.650 & 0.000 & 0.309 \\
EMP & $0.023^{*}$ & 0.012 & 1.970 & 0.080 & -0.003 \\
AST & $0.018^{* * *}$ & 0.005 & 3.670 & 0.005 & 0.476 \\
FAC & $0.035^{* * *}$ & 0.008 & 4.590 & 0.001 & 0.007 \\
OWW & -0.013 & 0.012 & -1.040 & 0.326 & 0.018 \\
cons & $0.498^{* * *}$ & 0.130 & 3.820 & 0.004 & -0.040 \\
\hline
\end{tabular}

***, ${ }^{* *}$, and ${ }^{*}$, respectively, indicate that the significance levels are 1 percent, 5 percent, and 10 percent.

TABLE 6: Mixed estimation results of technological innovation and GVC division status of high-end manufacturing in developing countries.

\begin{tabular}{lccccc}
\hline Variable & Coefficient & Standard error & $t$ & $P>|t|$ & Confidence interval \\
\hline PAT & $-0.024^{*}$ & 0.013 & -1.910 & 0.093 & -0.053 \\
EMP & $0.089^{* * *}$ & 0.015 & 6.140 & 0.000 & 0.005 \\
AST & $-0.011^{* * *}$ & 0.002 & -4.980 & 0.001 & -0.016 \\
FNC & 0.041 & 0.028 & 1.480 & 0.177 & -0.022 \\
OWW & $-0.043^{* *}$ & 0.019 & -2.310 & 0.049 & -0.006 \\
_cons & $0.479^{* *}$ & 0.202 & 2.370 & 0.045 & 0.106 \\
\hline
\end{tabular}

${ }^{* * *},{ }^{* *}$, and ${ }^{*}$, respectively, indicate that the significance levels are 1 percent, 5 percent, and 10 percent.

variables of human resources, fixed assets, financial development level, and level of openness to the outside world have a significant positive effect on the status of GVC's division of labor. After adding these four variables, the positive effect of technological innovation on GVC's division of labor has been weakened to a certain extent. However, in general, various variables have formed a good interaction relationship with GVC's division of labor, which has comprehensively enhanced the export value of intermediate products of high-end manufacturing.

4.4.2. Multiple Stepwise Regression Analysis of Developing Countries. Using the same method, this study performed a multiple stepwise regression analysis on developing countries, based on Model 1 through Model 4. The results are shown in Table 8 .

In Table 8, one can see that technological innovation in developing countries has always had a significant and negative effect on the status of GVC's division of labor, which further verifies the accuracy of the regression results. From the regression results of Models 2, 3, and 4, once sees that, after gradually adding in human capital variables, fixed asset variables, and financial development level, the negative impact of technological innovation on GVC's division of labor status has increased. Among all the variables, human capital had the most significant and most positive impact on
GVC's division of labor status, while the fixed assets variable had the most significant negative impact. On the one hand, these results suggest that human resources are therefore an important factor in enhancing the status of GVC's division of labor. On the other hand, they also show that there is a structural mismatch in high-end manufacturing fixed asset investment that serves exports. After including the level of openness to the outside world, the models suggest that the negative effect of technological innovation on GVC's division of labor status has been significantly weakened. Furthermore, the role of human capital in enhancing GVC's division of labor status is shown to have been significantly enhanced. Finally, this further emphasizes that a country's level of openness to the outside world is in fact an important measure for developing countries for enhancing their position in the status of the division of labor in the value chain.

4.5. Discussion. The impact of technological innovation in high-tech industries on GVCs is heterogeneous. In developed countries, technological innovation has a significant and positive effect on the division of labor status in GVCs. In contrast, in developing countries, technological innovation in high-tech industries has a significant inhibitory effect on the division of labor status in GVCs. The conclusion reached, as they pertain to developing countries, does not conform to the objective law of the technology industry. One important 
TABLE 7: Results of multiple stepwise regression in developed countries.

\begin{tabular}{|c|c|c|c|c|c|c|c|c|c|c|}
\hline \multirow[b]{2}{*}{ Variable } & \multicolumn{2}{|c|}{ Model 1} & \multicolumn{2}{|c|}{ Model 2} & \multicolumn{2}{|c|}{ Model 3} & \multicolumn{2}{|c|}{ Model 4} & \multicolumn{2}{|c|}{ Model I } \\
\hline & Coe. & $P>|t|$ & Coe. & $P>|t|$ & Coe. & $P>|t|$ & Coe. & $P>|t|$ & Coe. & $P>|t|$ \\
\hline _cons & $0.873^{* * *}$ & 0.000 & $0.697^{* * *}$ & 0.000 & $0.549^{* * *}$ & 0.000 & $0.420^{* * *}$ & 0.005 & $0.498^{* * *}$ & 0.004 \\
\hline PAT & $0.473^{* * *}$ & 0.000 & $0.440^{* * *}$ & 0.000 & $0.390^{* * *}$ & 0.000 & $0.394^{* * *}$ & 0.000 & $0.393^{* * *}$ & 0.000 \\
\hline EMP & & & $0.022^{* *}$ & 0.010 & -0.002 & 0.652 & $0.011^{*}$ & 0.071 & $0.023^{*}$ & 0.080 \\
\hline AST & & & & & $0.025^{* * *}$ & 0.001 & $0.018^{* * *}$ & 0.005 & $0.019^{* * *}$ & 0.005 \\
\hline FIN & & & & & & & $0.035^{* * *}$ & 0.001 & $0.035^{* * *}$ & 0.001 \\
\hline OWW & & & & & & & & & -0.013 & 0.326 \\
\hline
\end{tabular}

${ }^{* * *},{ }^{* *}$, and ${ }^{*}$, respectively, indicate that the significance levels are 1 percent, 5 percent, and 10 percent.

TABLE 8: Results of multiple stepwise regression in developing countries.

\begin{tabular}{|c|c|c|c|c|c|c|c|c|c|c|}
\hline \multirow[b]{2}{*}{ Variable } & \multicolumn{2}{|c|}{ Model 1} & \multicolumn{2}{|c|}{ Model 2} & \multicolumn{2}{|c|}{ Model 3} & \multicolumn{2}{|c|}{ Model 4} & \multicolumn{2}{|c|}{ Model I } \\
\hline & Coe. & $P>|t|$ & Coe. & $P>|t|$ & Coe. & $P>|t|$ & Coe. & $P>|t|$ & Coe. & $P>|t|$ \\
\hline _cons & $0.473^{* * *}$ & 0.000 & $0.422^{* * *}$ & 0.00 & $0.409^{* * *}$ & 0.000 & $0.185^{* *}$ & 0.036 & $0.479^{* *}$ & 0.045 \\
\hline PAT & $-0.015^{* * *}$ & 0.003 & $-0.036^{* * *}$ & 0.002 & $-0.038^{* * *}$ & 0.002 & $-0.043^{* * *}$ & 0.001 & $-0.024^{*}$ & 0.093 \\
\hline EMP & & & $0.030^{*}$ & 0.071 & $0.049^{* *}$ & 0.014 & $0.053^{* * *}$ & 0.009 & $0.089^{* * *}$ & 0.000 \\
\hline AST & & & & & $-0.009^{* * *}$ & 0.001 & $-0.009^{* * *}$ & 0.004 & $-0.011^{* * *}$ & 0.001 \\
\hline FIN & & & & & & & $0.067^{* * *}$ & 0.004 & 0.041 & 0.177 \\
\hline OWW & & & & & & & & & $-0.043^{* *}$ & 0.049 \\
\hline
\end{tabular}

${ }^{* * *},{ }^{* *}$, and ${ }^{*}$, respectively, indicate that the significance levels are 1 percent, 5 percent, and 10 percent.

reason for this may be that personnel investment, capital investment, and infrastructure construction have produced a more obvious crowding-out effect on technological innovation. In other words, although developing countries have invested a lot of resources in high-end manufacturing, they have not received effective positive feedback. Regarding this issue, the academic community has also carried out targeted research. The general conclusion is that technological innovation can be divided into imitative innovation and disruptive innovation, and only disruptive innovation can reshape the global value chain division of the labor system. When countries rely on the advantages of factor endowments to integrate into the global value chain, it has stimulated the imitative and innovative power of countries to a greater extent [17]. While accepting technological spillovers brought about by trade and investment, more resources have been invested in imitating innovation. This has led to a strong technological dependence on foreign advanced technology, hindering the subversive innovation power of various countries and thus being unable to enhance the GVC division of labor status [18]. In addition, technological innovation has obvious phases and heterogeneity to GVC's division of labor [19]. For most countries with development conditions, passively accepting the GVC division of labor is an inevitable requirement for the optimal allocation of global resources in the short term. To achieve the transition from passive to a dominant position, it will rely on the long-term rational allocation of innovative resources to promote technological fission.

\section{Conclusions}

There is a critical gap separating the status of the GVC division of labor between developed and developing countries. Additionally, the level of technological innovation is a key factor in the development of high-end manufacturing and the promotion of its GVC division of labor status. To clarify the degree of influence that technological innovation has on the domestic value-added export of high-end manufacturing, as it pertains to intermediate products of both developing and developed countries, this paper constructs a model for calculating the GVC division of labor in high-end manufacturing, and it also calculates the GVC division of labor in 43 major trade countries from 2000 to 2014 . This paper utilized the same method to ascertain the benign interaction between technological innovation and the status of the GVC division of labor, based on previous research results. Finally, the calculations, respectively, verified the role that technological innovation plays in both developed and developing countries regarding the GVC division of labor status in high-end manufacturing. The main conclusions are as follows:

(1) In developed countries, high-end manufacturing GVCs have a higher division of labor status, while GVCs in developing countries occupy a lower division of labor status. In the past 15 years, the strategic position of high-end manufacturing has been held by developed countries. High-end manufacturing in developed countries has garnered more significant profits from exporting intermediate goods and has a higher domestic value-added rate. In developing countries, high-end manufacturing's export profitability, with regard to intermediate products, is weak, and the domestic value-added rate is low. There is, therefore, much room for improvement for the GVC division of labor status in the high-end manufacturing industry.

(2) The effective allocation of both direct and indirect resources can help to promote the GVC division of 
labor status in developing countries. High-end manufacturing enterprises should therefore fully absorb high-end talent and inject decisive core power into the enterprise. Meanwhile, the national decision-making department should give full attention to the following: (1) the leading role of financial institutions in the real economy, (2) optimizing financial infrastructure, (3) improving financial efficiency, and (4) matching the supply structure of financial capital factors with the export demand of high-end manufacturing intermediate products. Thus, they could drive the high-end manufacturing status of the GVC division of labor in the industry to rise.

(3) For developing countries, an effective allocation of both direct and indirect resources can promote the GVC division of labor status. Therefore, high-end manufacturing enterprises should fully absorb highend talent and inject decisive core power into the enterprise. This would drive the high-end manufacturing status of the GVC division of labor in the industry to rise.

Finally, there are two identifiable shortcomings of this study. First, it was limited by its data source, which is current as of 2014. As such, the time span covered by this study is short, and it does not employ the latest data. As such, these results may only explain the real-world situation as it pertains to the investigation period. Additionally, a lack of original data results in a small number of samples, and therefore the empirical results pertaining to both developed and developing countries should not be regarded as offering a conclusion for all countries of the same type. Second, the research was only focused on empirical data, upon which it tested the relationship between technological innovation and GVC's division of labor status. To conclude, the internal mechanism should be explored further to offer ideas regarding resource allocation for developing countries in leveraging technological innovation to enhance GVC's division of labor status.

\section{Data Availability}

The data used in this study was obtained mostly from the WIOT of the WIOD, as well as the STAN Database for Structural Analysis (ISIC Rev. 4, SNA08) copy of the OECD.Stat database.

\section{Conflicts of Interest}

The authors declare that there are no conflicts of interest regarding the publication of this paper.

\section{Acknowledgments}

The study was supported by the Heilongiiang Province Philosophy and Social Science Planning Project "Research on the Structural Mismatch of Human Capital in Heilongjiang Province" (21JYC243) and special fund project of Heilongjiang University "Research on the Impact of
International Direct Investment on the Upgrading of my country's High-Tech Industry from the Perspective of Technology Innovation" (HDYJW201906).

\section{References}

[1] X. Dai, "How to "stabilize exports" in climbing global value chains: mechanism and empirical research," International Economic and Trade Exploration, vol. 2002, no. 54, pp. 75-96, 2021.

[2] D. Hummels, J. Ishii, and K. M. Yi, "The nature and growth of vertical specialization in world trade," Journal of International Economics, vol. 54, no. 1, p. 96, 2001.

[3] Z. Wang, W. Powers, and S. J. Wei, "Value chains in east asian production networks," in Proceedings of the USITC Working Paper, Washington, DC, USA, October 2009.

[4] R. Koopman, Z. Wang, W. Powers, and S. J. Wei, "Give credit where credit is due: tracing value added in global production chains," NBER Working Papers, 2010.

[5] G. M. Grossman and E. Helpman, "The politics of free - trade agreements," American Economic Review, vol. 85, no. 4, pp. 667-690, 1995.

[6] W. Y. Feng, L. I. Jian, and S. K. Zhao, "Impact of technological innovation on competitiveness of high-tech industry: an empirical analysis on 1995-2010 data," China Soft Science, no. 9, pp. 154-164, 2012.

[7] L. Yu and L. Q. Xu, "The influence of technological innovation on the trade competitiveness of high-tech products," Statistics and Information Forum, vol. 25, no. 5, pp. 76-80, 2010.

[8] Z. J. Chu, X. H. Huang, and H. Wang, "Does product innovation increase the mark-up rate of export enterprises?" International Trade Issues, no. 7, pp. 17-26, 2017.

[9] J. H. Zheng and Y. Zheng, "Intermediate product innovation in emerging economies drives the rise of global value chains-_an explanation based on China's experience," China's Industrial Economy, no. 5, pp. 61-79, 2020.

[10] H. X. Yang and H. G. Tian, "The technological progress of China's manufacturing industry and the rising position of the global value chain--based on the perspective of coupling and coordination," Journal of Anhui University (Philosophy and Social Sciences Edition), vol. 44, no. 6, pp. 130-144, 2020.

[11] D. X. Yu and H. Y. Liu, "Research on the impact of my country's independent innovation ability on export trade- - based on the empirical study of patent grant," International Trade Issues, no. 3, pp. 28-33, 2008.

[12] J. Wang and X. F. Fan, "Research on the impact of innovation on the complexity of export technology from the perspective of regional institutional quality," Humanities Magazine, no. 4, pp. 99-108, 2019.

[13] D. Haugh, A. Kopoin, E. Rusticelli, D. Turner, and R. Dutu, "Cardiac arrest or dizzy spell," OECD Economic Policy Paper, no. 18, 2016.

[14] L. N. Deng, "Research on FDI, international technology spillovers and China's manufacturing industry upgrading," Doctoral Dissertation, Shandong University, Jinan, China, 2015.

[15] Y. H. Fu, X. S. Ye, and Z. Wang, "The choice of technological progress path for optimizing manufacturing structure--based on the empirical analysis of dynamic panel," China's Industrial Economy, no. 9, pp. 78-90, 2014.

[16] Z. W. Peng and B. W. Zhang, "Intermediate trade, value chain embedding and international division of labor benefits: an analysis based on China," The World Economy, vol. 40, no. 10, pp. 23-47, 2017. 
[17] R. A. Lopez and N. Yadav, "Imports of intermediate inputs and spillover effects:evidence from Chilean plants," Journal of Development Studies, vol. 46, no. 8, 2010.

[18] W. G. Deng and R. Wang, "Global value chain fovernance and the transformation of export-oriented economy industries: taking the pearl river delta region as an example," Academic Research, no. 1, pp. 56-160, 2010.

[19] Y. Jiao and H. X. Yang, "The non-linear transmission of technological innovation to the climbing of China's manufacturing global value chain," Modern Economic Discussion, no. 7, pp. 99-107, 2020. 